\title{
Optimal Economical Sizing of Grid-Connected Hybrid Renewable Energy System
}

\author{
Mohammad Masih Sediqi, Masahiro Furukakoi, Mohammed E. Lotfy, Atsushi Yona and Tomonobu Senjyu \\ Department of Electrical and Electronics Engineering, University of the Ryukyus, Okinawa 903-0123, Japan
}

Received: December 19, 2016 / Accepted: February 15, 2017 / Published: April 30, 2017.

\begin{abstract}
In this paper, an optimized model is proposed to find the best values for decision variables to optimize the grid connected hybrid renewable energy system which consists of photovoltaic panels, wind turbines and battery bank for electrification to North-east region of Afghanistan to meet winter power shortages of the area. In the proposed model, there are three decision variables namely, the total area occupied by the set of PV panels, total swept area by the rotating turbines' blades, and the number of batteries. GA (genetic algorithm) is defined to find the optimal values of the decision variables. The objective of this research is to minimize the LCC (life cycle cost) of the hybrid renewable energy system, and ensuring at the same time systems reliability level which is measured in terms of LPSP (loss of power supply probability).
\end{abstract}

Key words: Grid-connected hybrid renewable energy system, optimized model, genetic algorithm.

\section{Nomenclature}

$\begin{array}{ll}\text { CPU } & \text { Central processing unit } \\ \text { DPSP } & \text { Deficiency of power supply probability } \\ \text { EC } & \text { Energy cost } \\ \text { EPG } & \text { Excess power generated } \\ \text { HES } & \text { Hybrid energy system } \\ \text { HRES } & \text { Hybrid renewable energy system } \\ \text { HOMER Hybrid optimization model for electric renewables } \\ \text { LCC } & \text { Life cycle cost } \\ \text { LPSP } & \text { Loss of power supply probability } \\ \text { LOLP } & \text { Loss of load probability } \\ \text { LEC } & \text { Levelized energy cost } \\ \text { LUC } & \text { Life cycle unit cost } \\ \text { LUEC } & \text { Levelized unit electricity cost } \\ \text { NEPS } & \text { Northeast power system } \\ \text { REPG } & \text { Relative excess power generated } \\ \text { RES } & \text { Renewable energy system } \\ \text { SEPS } & \text { Southeast power system } \\ \text { TED } & \text { Total energy deficit } \\ \text { TNPC } & \text { Total net present cost } \\ \text { UEP } & \text { Unutilized energy probability }\end{array}$

Corresponding author: Mohammad Masih Sediqi, master student, research fields: renewable energy economics, energy storage and power optimization.

\section{Introduction}

Despite having enormous renewable energy sources such as solar, wind, hydro and geothermal, Afghanistan is still suffering from energy crises. Still only $30 \%$ of the total population has access to electricity. In the rural area, which makes almost $70 \%$ of Afghanistan population, just $10 \%$ has access to electricity. Afghanistan imports $78 \%$ of electrical energy from its neighbor countries (Uzbekistan, Turkmenistan, Tajikistan, and Iran) and the remaining $22 \%$ gets from its own sources, mainly from hydro [1].

According to preliminary estimation of the National Renewable Energy Laboratory of the United States, Afghanistan's technical solar potential is more than 200 gigawatts (GW), and technical wind potential exceeds $66 \mathrm{GW}$ [2]. The existing power system of Afghanistan is operated in islanded areas depending on the source of generation and impacts. Currently, there are within Afghanistan three distinct geographically separate transmission networks:

- The NEPS (northeast power system): Nangarhar/Kabul/Parwan/Ghori/Balkh (Presently 
supplied by existing hydropower projects, a minor share from diesels and a major share of imports);

- The SEPS (southeast power system): Kandahar and surrounding region (currently supplied by existing hydropower projects);

- Herat (presently covered by imports from Iran and Turkmenistan). In addition, several towns (such as Aybak and Ghazni) have their own diesel plants and distribution [3].

As aforementioned, the NEPS of Afghanistan is supplied by existing hydropower and diesel projects of Afghanistan and imported power from Uzbekistan and Tajikistan. Hydropower plants in Afghanistan are seasonal; during winter, there is not enough water for power generation. On the other hand, Tajikistan exports their surplus power only during summer. Tajikistan's power supply is dominated by hydropower plants. During winter, due to the seasonal problem of hydropower plants and high load demand for heating, Tajikistan exports limited amount of electricity. So, most of power is provided by Uzbekistan. The amount of electrical energy from Uzbekistan cannot cover the load demand during some hours. As a result, the NEPS has faced most hours blackout during winter. However, this problem does not exist in summer. In summer, Tajikistan has excess power, also up to some extent, Afghanistan has its own generation of electricity.

In this research, renewable energy sources are introduced and added to the grid to meet the load demand. Due to the stochastic nature of renewable sources, it is preferable to use a hybrid renewable energy system by which the system's reliability increases. Among the Hybrid renewable energy system, the combination of photovoltaic (PV) panels, WTs (wind turbines) and battery bank is usual. In $\mathrm{PV} / \mathrm{WT} /$ battery system, the battery bank plays the role of the storage system and is used to store excess energy for the later use in deficit generating conditions. If the hybrid systems are optimized, they would be cost efficient and more reliable.
Many authors have worked on optimization of hybrid renewable energy system with different techniques and objectives. Hong and Lian [4] introduced a new method using Markov-based GA for obtaining optimal sizes of hybrid wind/PV/diesel units in a stand-alone power system. Their objective is the minimization of cost considering both reliability and $\mathrm{CO}_{2}$ emission constraints. It is shown that Markov-based GA can help reduce CPU (central-processing unit) times and provide competitive cost which does not make any difference for different LOLP (loss of load probability) and $\mathrm{CO}_{2}$ emission constraints. An iterative procedure for optimization of a hybrid system consists of wind, PV and battery is presented by Prasad and Natarajan [5], based on DPSP (deficiency of power supply probability), REPG (relative excess power generated), UEP (unutilized energy probability), LCC (life cycle cost), LEC (levelized energy cost) and LUC (life cycle unit cost) of power generation with battery bank. In Ref. [6], Caballero et al. developed a method for the optimal sizing of a grid-connected HES (hybrid energy system) based on two different incentive rules for nonconventional renewable energy: selling the excess power generated by the system to the grid at a fixed price and net metering. The objective is to minimize the LCC of the system subject to some constraints. An optimization model is proposed for a hybrid renewable energy system (PV/WT/battery) for electrification to a small area in Kerman, Iran by Askarzadeh and Leandro [7]. Different PSO (Particle swarm optimization) variants are used for finding the optimal values of decision variables for the minimization of LCC. The results with adaptive inertia weight-based PSO algorithms are better than others. Also, among the various combination of Hybrid renewable energy system, the combination of $\mathrm{PV} / \mathrm{WTs} /$ battery is the most cost-effective and ensured. The $\varepsilon$-constraint method developed by Sharafi and Tarek [8] is applied to minimize loss of load probability, $\mathrm{CO}_{2}$ emission and total cost of a hybrid 
renewable energy system. A PSO simulation based method is proposed for solving the optimization problem. A comparison is done between a grid connected HRES and a standard grid operation based on environmental and economic effects. The software HOMER is used for sizing the hybrid renewable energy system. The results reveal a reduction of HRES both in cost of energy and emissions of $\mathrm{CO}_{2}$, $\mathrm{SO}_{2}$ and $\mathrm{NO}_{\mathrm{X}}$ compared to the standard grid power system. Kaabeche et al. [9], recommend a model for a grid-independent hybrid system consists of photovoltaic and wind. An iterative optimization technique has been used to minimize two objective functions: DPSP (deficiency of power supply probability) and LUEC (levelised unit electricity cost). Methodologies have been presented to model HRES components, HRES design and evaluation by Deshmukh [10]. Arash et al. [11] accomplished feasibility study for various hybrid diesel-RES and grid-RES energy systems using the software HOMER for the Binalood region in Iran. Findings show in terms of both economic and environmental the benefits of renewable energy sources in the area. And a techno-economic approach is developed by Abdelhamid and Rachid [12] for sizing optimization of stand-alone $\mathrm{PV} /$ wind/diesel hybrid system with battery storage. The proposed approach takes into consideration two models: the reliability model under the TED (total energy deficit) concept and the economic model based on TNPC (total net present cost) and EC (energy cost). Finally, the optimal configuration is finding by the combination of these two models.

In this paper, two objectives are considered. These are the minimization of cost and the maximization of system reliability. The purpose of this paper is to optimize the grid connected hybrid renewable energy system in terms of total LCC, and LPSP (loss of power supply probability) for the electrification of Northeast part of Afghanistan. In this research, the GA (genetic algorithm) is used to find the optimal values of three decision variables namely, the total area occupied by the PV panels, total swept area by the rotating turbines' blades, and the number of batteries.

\section{Grid Connected Hybrid Renewable Energy System}

The configuration of the grid-connected hybrid renewable energy system is depicted in Fig. 1. The system consists of the grid (NEPS of Afghanistan), PV array, wind turbines, battery bank, inverter, and a converter. Fig. 2 shows the NEPS of Afghanistan. The NEPS of Afghanistan is an isolated power system supplied by three sources. The first source is from Afghanistan's own power plants with the total capacity of $300 \mathrm{MW}$. The second is from Uzbekistan with $300 \mathrm{MW}$ potential. The last source is from Tajikistan which feeds the grid with $50 \mathrm{MW}$. The total output power of the grid is $650 \mathrm{MW}$. This amount of power covers the load demand in some non-peak hours. However, during peak hours the grid cannot meet the load demand. Thus, the hybrid renewable energy system is added to the grid power to cover the load demand. The operation mode of the proposed system is as follows: In normal operation, the grid and hybrid system supplies the load demand. The surplus energy from the grid, PV and wind turbines above the hourly demand is stored in the battery until the battery is full charged. When the energy required is greater than the energy generated, the battery bank will be used to satisfy the load demand.

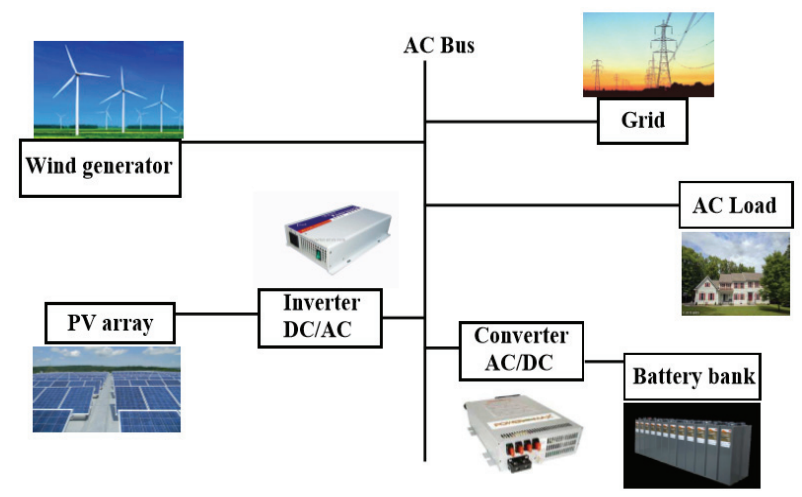

Fig. 1 Configuration of grid-connected hybrid renewable energy system. 


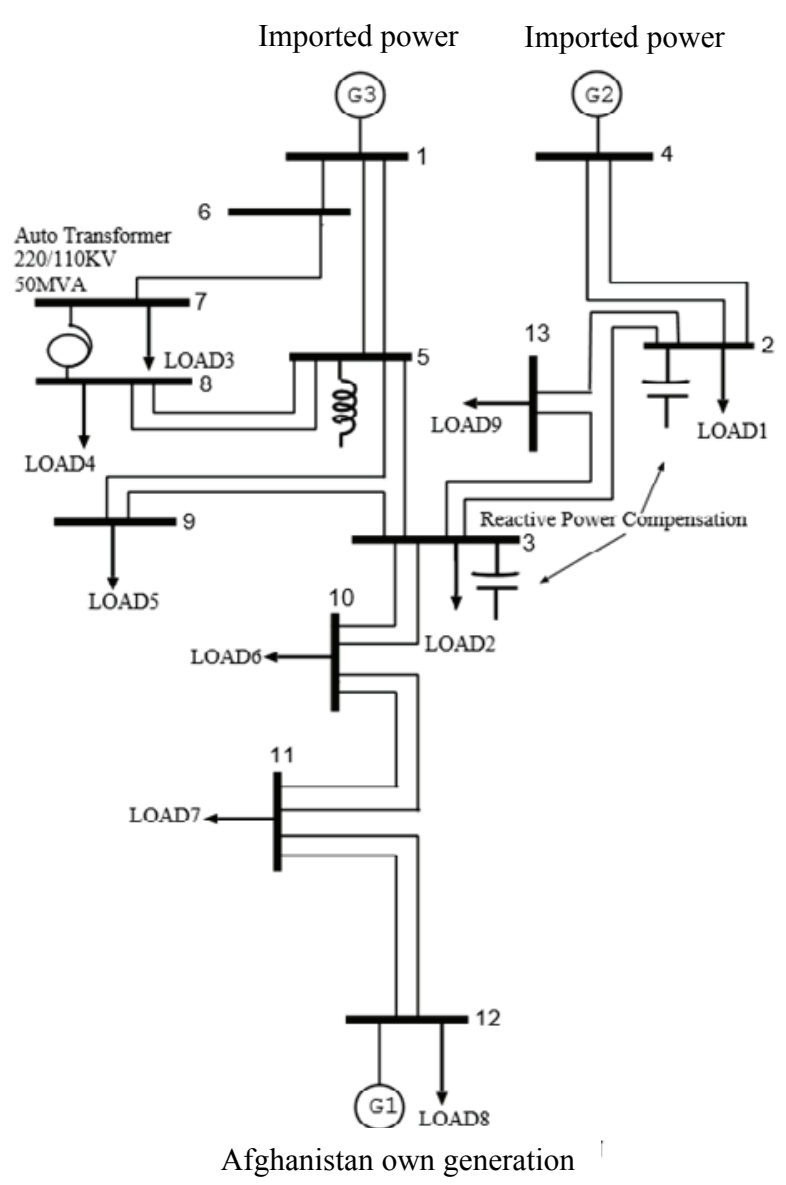

Fig. 2 Northeast power system of Afghanistan.

\section{Models}

Reliability and cost are the two objectives considered in this study. In order to find the objectives, technical and economical modeling of each component of the system is required. The following subsections describe the modeling of the components:

\subsection{PV Array Output Power}

The following is the equation for the power supplied by a set of PV panels at hour $t$ :

$$
P_{P V}(t)=\eta_{P V} \cdot A_{P V} \cdot S(t)
$$

where, $\eta_{P V}$ denotes $\mathrm{PV}$ panels efficiency, $A_{P V}$ is the total area occupied by PV panels in $\mathrm{m}^{2}$ and $S(t)$ is the hourly solar insolation in $\mathrm{kW} / \mathrm{m}^{2}$.

\subsection{Wind Generator Output Power}

Fig. 3 depicts a model for output power calculation

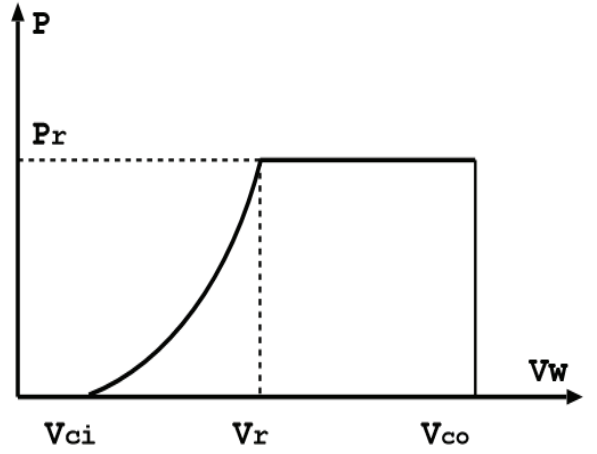

Fig. 3 Typical wind generator power curve.

of wind turbines. There is no power generation from wind turbines below cut-in speed $\left(V_{c i}\right)$. As wind speed increases above cut-in speed, the power generated by the turbines increases as the cube of wind speed, until reaching a maximum point at rated speed $\left(V_{r}\right)$. This is the power the wind turbine is designed for, rated power $\left(P_{r}\right)$ in $\mathrm{kW}$. As it is seen from the figure, at some point, the wind speed is very strong that there is danger to the wind turbine. This is called cut-off speed $\left(V_{c o}\right)$, and the machine should be stopped. The mathematical model of this behaviour is as follows:

$$
\begin{aligned}
& P_{w}(t) \\
& =\left\{\begin{array}{cc}
0 & v(t) \leq V_{c i} \text { or } v(t) \geq V_{c o} \\
P_{r} \frac{v^{3}(t)-V_{c i}{ }^{3}}{V_{r}^{3}-V_{c i}{ }^{3}} & V_{c i}<v(t)<V_{r} \\
P_{r} & V_{r}<v(t)<V_{c o}
\end{array}\right\}
\end{aligned}
$$

where, $v(t)$ is the wind speed in an instant of time $t$ in $\mathrm{m} / \mathrm{s}$.

The rated power of wind turbine generator at hour $t$ is calculated by the following Eq. (3):

$$
P_{r}=\frac{1}{2} \cdot C_{p} \cdot \rho_{a} \cdot \eta_{g} \cdot A_{w} \cdot V_{r}^{3}
$$

where, $C_{p}$ is power coefficient and it is the ratio of the power output of a wind generator divided by maximum power. $\rho_{a}$ is the air density in $\mathrm{kg} / \mathrm{m}^{3}, \eta_{g}$ is the efficiency of wind turbine, and $A_{w}$ is the total swept area by the rotating turbines' blades in $\mathrm{m}^{2}$. As it is seen, wind power is proportional to the cube of wind speed, so even modest increase in wind speed can affect the wind power. In order to get higher wind 
output, one way is to mount the turbine on a taller tower. Surface winds are getting slowed by high irregularities such as forests and buildings. The following equation is for the effect of roughness of the earth's surface on the wind speed:

$$
\frac{V}{V_{0}}=\left(\frac{h}{h_{0}}\right)^{\alpha}
$$

where, $V$ and $V_{0}$ are the wind speeds at height $h$ and $h_{0}$ respectively, and $\alpha$ is the roughness factor. The $\alpha$ value is less than 0.1 for flat land, water or ice and more than 0.25 for forested landscapes.

\subsection{Battery}

The amount of energy generated by the grid, PV panel array and wind turbine at hour $t$ is:

$$
P_{g}(t)=P_{P V}(t)+P_{W}(t)+P_{\text {grid }}
$$

Depending on the load demand $\left(P_{l}\right)$, the amount of $P_{g}$ at a specific time can be enough or not to meet the power demand. As a result, state of charge of the battery $(S O C)$ at any time $t$ can be found as follows:

- If $P_{g}(t) \geq \frac{P_{l}(t)}{\eta_{i n v}}$, then there exists surplus energy by which the battery can be charged. During charging, the $S O C$ is calculated as follows:

$$
\begin{aligned}
\operatorname{SOC}(t)=\operatorname{SOC}( & t-1) \cdot(1-\sigma) \\
& +\left(P_{g}(t)-\frac{P_{l}(t)}{\eta_{i n v}}\right) \cdot \eta_{b c}
\end{aligned}
$$

where, $\operatorname{SOC}(t)$ and $\operatorname{SOC}(t-1)$ are states of charge of the battery in time $t$ and $t-1$ respectively. $\sigma$ is hourly self-discharge rate, $\eta_{i n v}$ is efficiency of the inverter and $\eta_{b c}$ is the battery charging efficiency.

Since state of charge of the battery cannot exceed the maximum state of charge, so during optimization the following constraint should be considered:

$$
\operatorname{SOC}(t) \leq S O C_{\max }
$$

where, maximum state of charge of the battery is the nominal capacity of the battery bank $\left(C_{b}\right)$.

- If $P_{g}(t) \leq \frac{P_{l}(t)}{\eta_{i n v}}$, then there exists deficit of energy from $P_{g}$ and the load is supplied by the storage systems. During discharging, the state of charge is:

$$
\begin{aligned}
\operatorname{SOC}(t)=\operatorname{SOC}( & t-1) \cdot(1-\sigma) \\
& +\left(\frac{P_{l}(t)}{\eta_{\text {inv }}}-P_{g}(t)\right) / \eta_{b d}
\end{aligned}
$$

where, $\eta_{b d}$ is discharge efficiency of the battery.

For stretching lifespan of the battery, the state of charge should not be less than the minimum state of charge, so during optimization the following constraint should be taken in discharge time of the battery:

$$
\operatorname{SOC}(t) \geq S O C_{\text {min }}
$$

The minimum state of charge can be obtained as follows:

$$
S O C_{\min }=(1-D O D) \cdot C_{b}
$$

where, $D O D$ is the maximum depth of discharge.

\section{Reliability Evaluation Based on LPSP}

One of the two objectives in this study is the reliability of the system. It is the measure of quality of power supply. Any proposed design will have a certain reliability. In this study, reliability of the system is expressed in terms of LPSP which is defined as the ratio of deficit power over the total required power. The LPSP for a study period $\mathrm{T}$ is calculated as follows: As described in previous subsection, when the power demand of the load is greater than the total energy generated by the grid, PV array, and WTs, the battery bank will be used to assure the load demand. In this case, the new state of charge at hour $t$ is calculated using Eq. (8). During discharging if the state of charge becomes less than the minimum state of charge, it means a portion of the load is not covered. So, $S O C$ is set to $S O C_{\min }$ and loss of power is defined as:

$$
\begin{gathered}
\operatorname{LPS}(t)=P_{l}(t)-\left[P_{g}(t)+S O C(t-1)\right. \\
\left.-S O C_{\text {min }}\right] \cdot \eta_{\text {inv }}
\end{gathered}
$$

The LPSP for a considered period $t$ ( 24 hours in this study), can be defined as the ratio of all the $\operatorname{LPS}(t)$ values for that period to the sum of the load demand. It is defined as follows: 


$$
L P S P=\frac{\sum_{t=1}^{T} \operatorname{LPS}(t)}{\sum_{t=1}^{T} P_{l}(t)}
$$

LPSP means the load is satisfied or not satisfied. It is defined by a number between 0 and 1. LPSP of 1 means the load will never be covered and LPSP of 0 means the load will be always covered.

Also, during charging of the battery, when the state of charge of the battery bank reaches a maximum value, $S O C_{\text {max }}$, the control system stops the charging process. The EPG (excess power generated) unutilized by the system is an important parameter. Its value varies due to the variation of hourly load demand, solar insolation, wind velocity, and state of charge of the battery bank. The EPG can be defined at hour $t$ as follows:

$$
\begin{aligned}
E P G(t)=P_{g}(t) & -\left[P_{l}(t) / \eta_{i n v}\right. \\
+ & \left(S O C_{\max }-S O C(t-1)\right) \\
& \left./ \eta_{b c}\right]
\end{aligned}
$$

The REPG (relative excess power generated), defined as the ratio of surplus power to the sum of load demand during the considered period is calculated by the following equation:

$$
R E P G=\frac{\sum_{t=1}^{T} E P G(t)}{\sum_{t=1}^{T} P_{l}(t)}
$$

\section{Economic Analysis}

The LCC of each component of the hybrid renewable energy system is the sum of its capital cost, operating and maintenance cost and replacement cost minus salvage cost:

$$
L C C=C+O M_{n p v}+R_{n p v}-S_{n p v}
$$

where, $C, O M, R$ and $S$ are the capital cost, operating and maintenance cost, replacement cost and salvage cost in $\$$ respectively. The $n p v$ subscript means the present value of each factor.

Now the total LCC of the hybrid renewable energy system is the sum of LCC of all the components:

$$
L C C=L C C_{P V}+L C C_{W}+L C C_{b a t}
$$

The LCC of each component is obtained as follows.

\subsection{PV Array LCC}

The capital cost of the investment for PV array is equal to the initial cost $\$ / \mathrm{m}^{2}$ of PV array multiplied by the total area $\mathrm{m}^{2}$ occupied by PV array:

$$
C_{P V}=\alpha_{P V} \cdot A_{P V}
$$

The total operation and maintenance cost of PV array per year is $O M_{P V}=\beta_{P V} \cdot A_{P V}$, where $\beta_{P V}$ is the annual operation and maintenance cost in $\$ / \mathrm{m}^{2} /$ year. Now, if the cost grows at an annual rate of $\mu_{P V}$, the sum of the net present value of operating and maintenance cost for PV array is:

$$
O M_{n p v, P V}=\beta_{P V} \cdot A_{P V} \cdot \sum_{j=1}^{N}\left(\frac{1+\mu_{P V}}{1+i}\right)^{j}
$$

where, $i$ is the interest rate and $N$ denotes the project lifetime. By assuming the lifetime span of PV panels equal to the project lifetime, the total replacement cost for PV panels is zero $\left(R_{P V}=0\right)$.

By considering the resale price of $\lambda_{P V}$ in $\$ / \mathrm{m}^{2}$ the total income obtained from resale is:

$$
S_{n p v, P V}=\lambda_{P V} \cdot A_{P V} \cdot\left(\frac{1+\delta}{1+i}\right)^{N}
$$

where, $\delta$ denotes the inflation rate. At last, the LCC of PV array is obtained by using Eq. (15).

\subsection{Wind Turbines LCC}

The LCC of the WTs is obtained same as for the PV panels, except only replacing the subscript PV by $w$.

\subsection{Battery LCC}

The capital cost of the investment for the storage system is:

$$
C_{b a t}=N_{b a t} \cdot \alpha_{b a t}
$$

where, $N_{b a t}$ is the number of batteries and $\alpha_{b a t}$ denotes the unit cost of battery in $\$$. The lifetime of battery $\left(L_{b a t}\right)$ is less than that of the PV array and WTs. Therefore, addition investments are required before the end of the project. The number of times during lifetime of a project that a battery is required to be replaced is $X_{r}=\frac{N}{L_{b a t}}-1$. In this research, the lifetime of the project is selected 20 years and the lifetime of each battery is 5 years, so each battery 
must be replaced 3 times during the lifetime of the project. Finally, the net present value of the replacement cost is:

$$
R_{n p v, b a t}=N_{b a t} \cdot \alpha_{b a t} \cdot \sum_{j=5,10,15}\left(\frac{1+\mu_{b a t}}{1+i}\right)^{j}
$$

In this study, the operation and maintenance cost and salvage value of the storage systems are neglected.

\section{Multi Objective Functions and Constraints}

In this research, two objective functions are considered to be minimized. The first objective is LCC of the project, and the second one is the minimization of LPSP. So, the fitness functions are defined by:

$$
\begin{gathered}
\text { Min.LCC } \\
\text { Min.LPSP }
\end{gathered}
$$

where,

$$
\begin{gathered}
L C C=\sum_{k \in P V, w, b a t} C_{k}+O M_{n p v, k}+R_{n p v, k} \\
-S_{n p v, k} \\
L P S P=\frac{\sum_{t=1}^{T} L P S(t)}{\sum_{t=1}^{T} P_{l}(t)}
\end{gathered}
$$

Besides, the constraints are mentioned in the part of the state of charge of the battery. The restrictions in the objective functions are:

$$
\begin{gathered}
A_{P V} \geq 0 \\
A_{w} \geq 0 \\
N_{b a t} \geq 0 \\
R E P G<\epsilon
\end{gathered}
$$

where, $\epsilon$ is a very small number less than $10^{-4}$.

\section{Genetic Algorithm}

GA (genetic algorithm) is based on natural selection, the process that drives biological evolution. It is an algorithm for the solution of both constrained and unconstrained optimization problems. In every iteration, GA randomly selects individuals from the current population called parents and uses them to produce next generation called children. After successive iterations, the population evolves toward an optimal solution. Before explaining how GA works some parameters need to be described.

\subsection{GA Parameters}

\subsubsection{Fitness Functions}

The fitness function is the objective function one desires to optimize. GA aims to find the minimum or maximum of the fitness function.

\subsubsection{Individuals}

An individual is any point to which one can apply the fitness function. The value of the fitness function for an individual is its score.

\subsubsection{Populations and Generations}

A population is an array of individuals. In GA, the same individual can appear more than once in the population. At each generation, GA performs a series of computations to produce a new population. Each successive population is called a new generation.

\subsubsection{Diversity}

The average distance between individuals in a population is called diversity. If the space is large, then there is high diversity and if the space is small, so there is low diversity. Diversity is important in GA, because it enables the algorithm to search a larger region of the area.

\subsubsection{Fitness Values and Best Fitness Values}

The value of the fitness function for an individual is the fitness value of that individual. And the best fitness value for a population is the smallest fitness value for any individual in the population.

\subsubsection{Parents and Children}

GA selects individuals in the current population which is called parents for creation of individual in the next generation which is called children. The algorithm selects parents that have better fitness values.

\subsection{How GA Works}

GA works as the following steps: 


\section{Step 1: Initial Population}

GA starts with the creation of random initial populations. The default value of population size in the population options is 20 individuals. However, one can change the population size as want.

\section{Step 2: Calculation of Fitness Function}

The individuals are putted into fitness function and its value is calculated.

\section{Step 3: Creating Next Generation}

At each step, GA uses the current population to create the children that make up the next generation. GA creates three types of children for the next generation: (1) Elite children; (2) Crossover children; (3) Mutation children.

\section{Step 4: Stopping Conditions for $G A$}

If the stopping condition is met, the algorithm is stopped and the fitness values are selected as optimal solution, otherwise steps 2-3 are repeated.

\section{Simulation Results and Discussions}

\subsection{Simulation Inputs}

This research is for the electrification of Northeast region of Afghanistan. The model is proposed and for the optimization of the model some data such as daily solar radiation, wind speed, load demand and grid power are required. Figs. 4-6 show the input data used in the model. For more information, the average monthly wind speed and solar radiation of the site are depicted in Figs. 7 and 8. The values of the model parameters used in this study are shown in Table 1.

\subsection{Simulation Results}

Two fitness functions are proposed to be minimized, the total LCC of the project, and the LPSP. GA has been applied to get the optimal values of the decision variables to make the two objective functions minimized. For the simulation of the proposed methodology, MATLAB is used.

As discussed in the introduction part, most hours the grid cannot cover the daily load demand. So, hybrid renewable energy system (PV/WT/battery) is

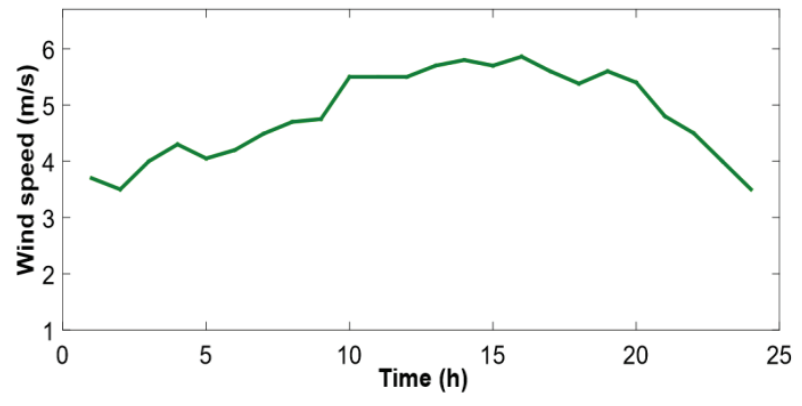

Fig. 4 Daily wind speed.

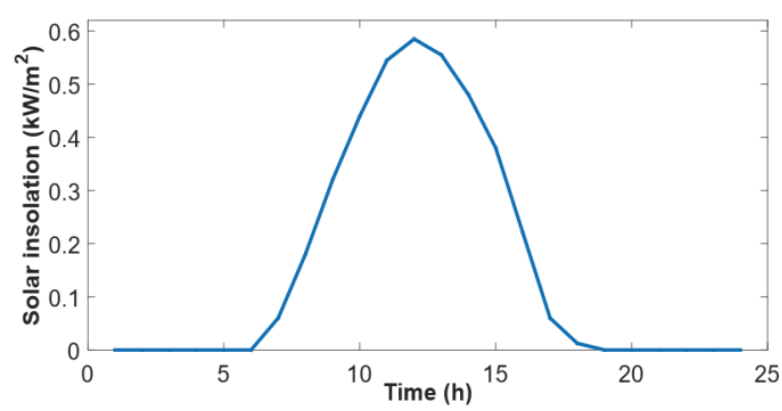

Fig. 5 Daily solar radiation.

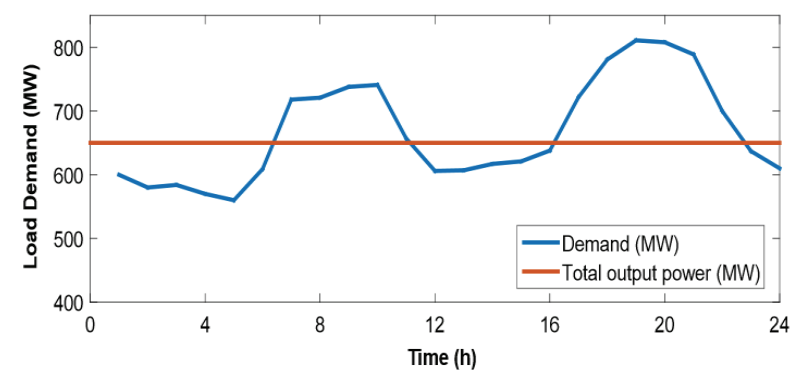

Fig. 6 Daily load profile.

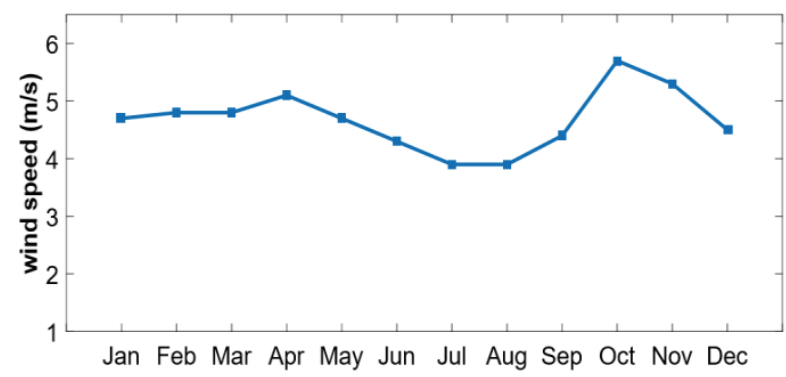

Fig. 7 Average monthly wind speed during one year.

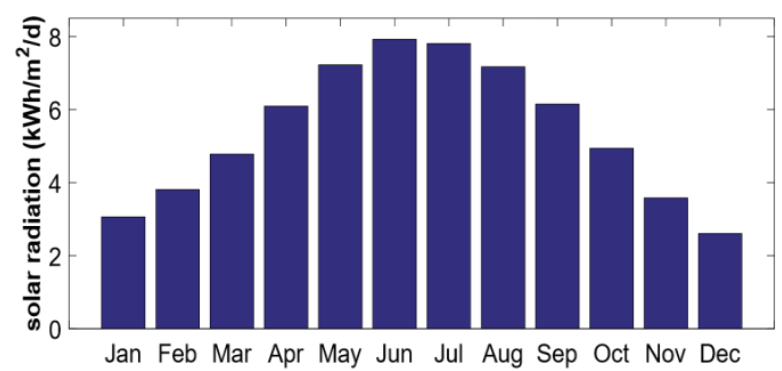

Fig. 8 Average monthly solar radiation during one year. 
Table 1 Parameters used in this study.

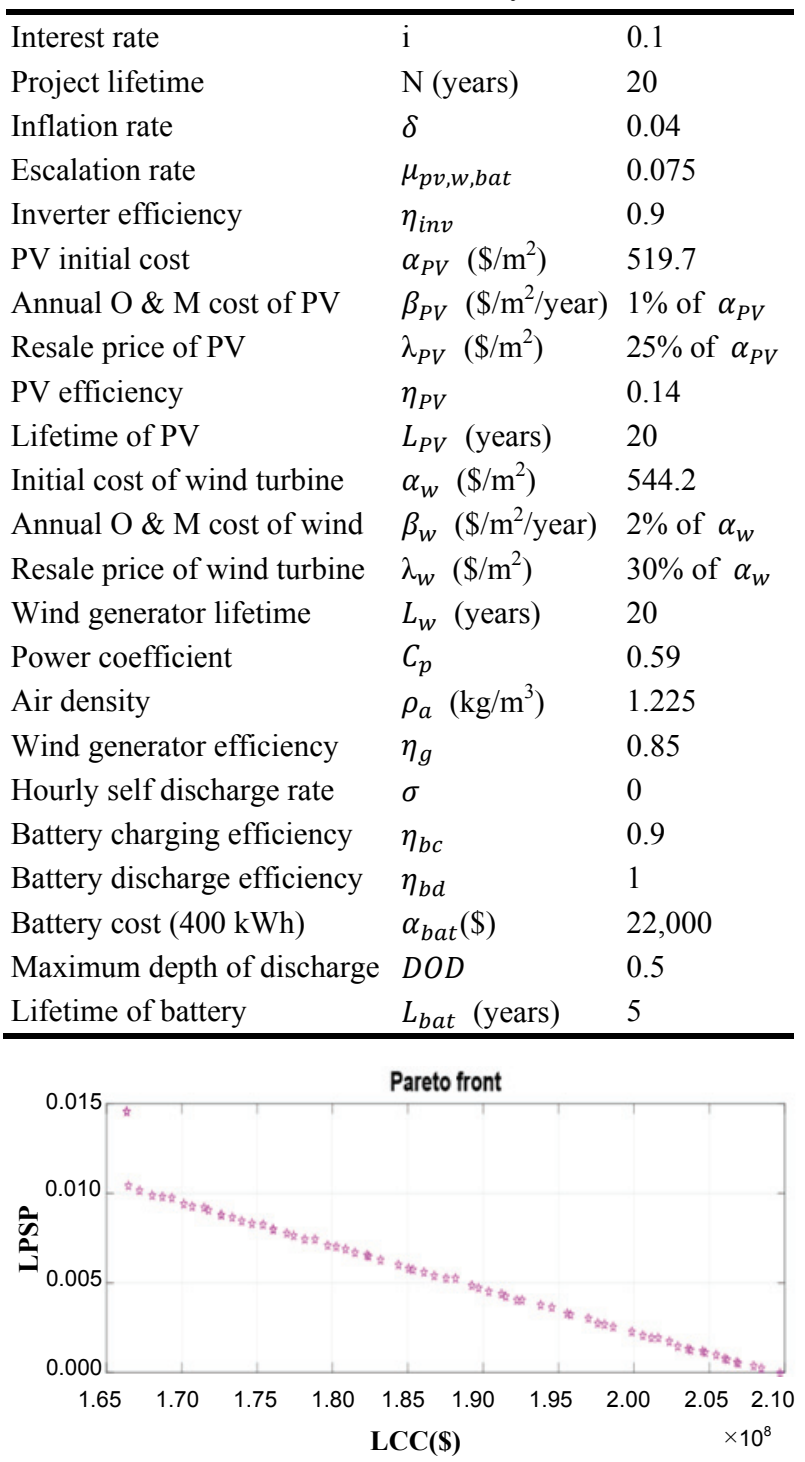

Fig. 9 LCC vs. LPSP.

introduced to be added to the grid. Now, the output power of PV panels and WTs are added to the grid to meet the demand. The simulation result is shown in Fig. 9. As it is seen, the LCC decreases when LPSP increases and rises when LPSP gets down. The optimal size and the minimized values of the two objectives are shown in Table 2. Fig. 10 depicts the power generated by grid, PV panels and WTs, and the load profile. The battery bank stores the surplus power and delivers it in deficit conditions. State of charge of the battery bank is shown in Fig. 11. Finally, Fig. 12 depicts the generation power of the optimized model.

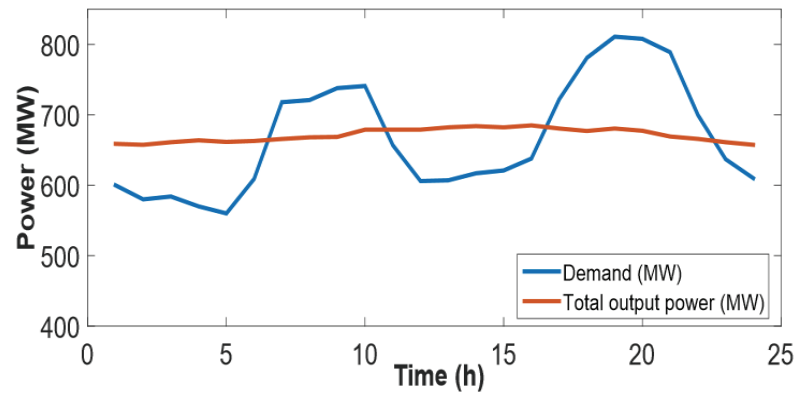

Fig. 10 Produced power of grid, PV and WTs.

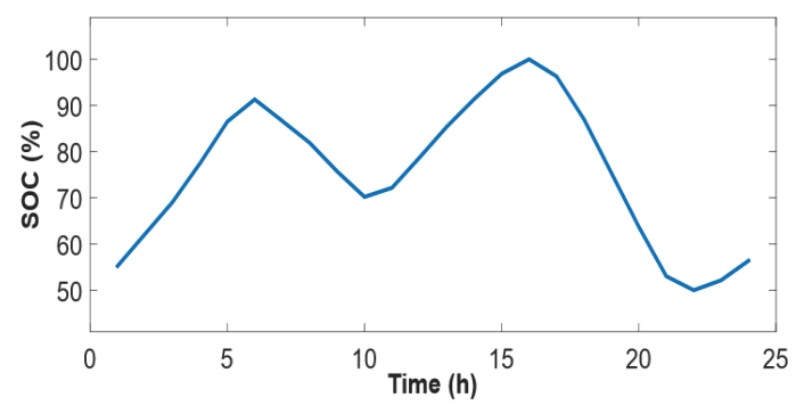

Fig. 11 State of charge.

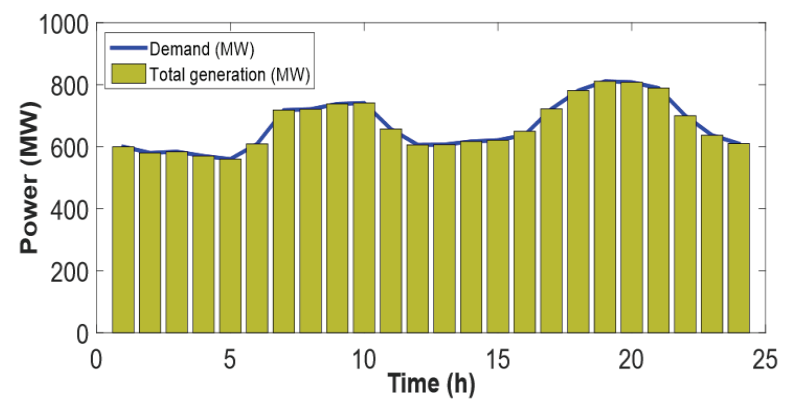

Fig. 12 Generation power of the optimized model.

Table 2 Optimal size of the grid-connected hybrid system.

\begin{tabular}{lllll}
\hline$A_{P V}\left(\mathrm{~m}^{2}\right)$ & $A_{w}\left(\mathrm{~m}^{2}\right)$ & $N_{\text {bat }}$ & LPSP & LCC $(\$)$ \\
\hline 265 & 567 & 2,800 & 0 & $209,620,000$ \\
\hline
\end{tabular}

As it is seen there is no mismatch power between total generated power and load demand.

\section{Conclusions}

An optimization model for designing a grid-connected hybrid renewable energy system is developed in this paper. The proposed power system comprises of PV panels, WTs, and battery bank integrated to the grid to cover winter power shortages of the northeast region of Afghanistan. GA has been used to find the optimal values of the three decision variables, namely the total area occupied by PV panels, 
total swept area by rotating WTs' blades and the number of battery. The proposed methodology has been applied to minimize two objectives: LPSP and the LCC of the system. The simulation results reveal the ability of the proposed algorithm for producing optimum results.

\section{References}

[1] Ministry of Energy and Water of Afghanistan. Retrieved January 2016, www.mew.gov.af.

[2] Islamic Republic of Afghanistan: Renewable Energy Development. December 2014.

[3] FICHTNER. "Islamic Republic of Afghanistan: Power Sector Master Plan.”

[4] Hong, Y.-Y., and Lian, R.-Ch. 2012. "Optimal Sizing of Hybrid Wind/PV/Diesel Generation in a Stand-Alone Power System Using Markov-Based Genetic Algorithm.” IEEE Transactions on Power Delivery 27 (2): 640-7.

[5] Prasad, A. R., and Natarajan, E. 2006. "Optimization of Integrated Photovoltaic-Wind Power Generation Systems with Battery Storage." Energy 31 (12): 1943-54.

[6] Caballero, F., Sauma, E., and Yanine, F. 2013. "Business Optimal Design of a Grid-Connected Hybrid PV
(Photovoltaic)-Wind Energy System without Energy Storage for an Easter Island's Block." Energy 61 (November): 248-61.

[7] Askarzadeh, A., and dos Santos Coelho, L. 2015. "A Novel Framework for Optimization of a Grid Independent Hybrid Renewable Energy System: A Case Study of Iran." Solar Energy 112 (1): 383-96.

[8] Sharafi, M., and ELMekkawy, T. Y. 2014. "Multi Objective Optimal Design of Hybrid Renewable Energy Systems Using PSO-Simulation Based Approach." Renewable Energy 68 (August): 67-79.

[9] Kaabeche, A., Belhamel, M., and Lbtiouen, R. 2011. "Sizing Optimization of Grid-Independent Hybrid Photovoltaic/Wind Power Generation System." Energy 36 (2): 1214-22.

[10] Deshmukh, M. K., and Deshmukh, S. S. 2008. "Modeling of Hybrid Renewable Energy Systems." Renewable Energy Reviews 12 (1): 235-49.

[11] Asrari, A., Ghasemi, A., and Javidi, M. H. 2012. "Economic Evaluation of Hybrid Renewable Energy Systems for Rural Electrification in Iran-A Case Study." Renewable Energy Reviews 16 (5): 3123-30.

[12] Kaabeche, A., and Ibtiouen, R. 2014. "Techno-Economic Optimization of Hybrid Photovoltaic/Wind/Diesel/ Battery Generation in a Stand-Alone Power System." Solar Energy 103 (May): 171-82. 